Historic, archived document

Do not assume content reflects current scientific knowledge, policies, or practices. 



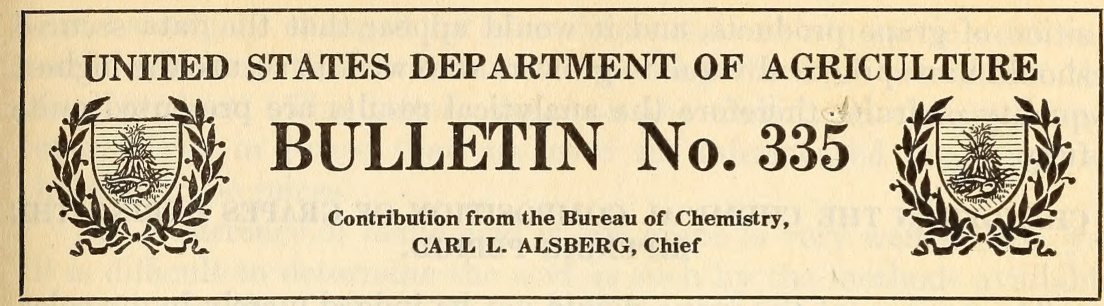

Washington, D. C.

April 11, 1916

\section{DEVELOPMENT OF SUGAR AND ACID IN GRAPES DURING RIPENING.}

By William B. Alwood, Enological Chemist, with the collaboration of B. J. Hartmann, J. R. Eoff, M. J. Ingle, and S. F. Sherwood.

\section{CONTENTS.}

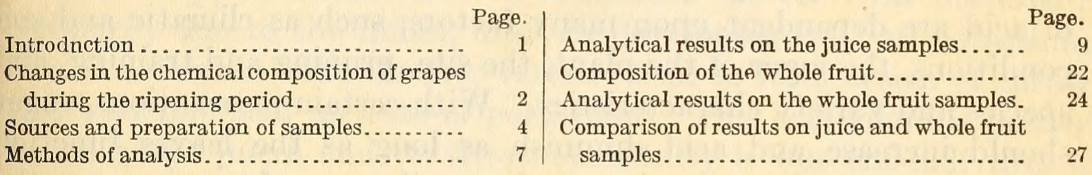

\section{INTRODUCTION.}

In Bulletin 140, Bureau of Chemistry, a preliminary report is made on the changes in sugar and acid content of several varieties of grapes as determined in 1909 and 1910 during a period of several weeks previous to ripening and at full maturity. The results of a further and more extended examination of several of these varieties of grapes made during the seasons of 1911 and 1912 are presented in this bulletin. The examinations were made at Sandusky, Ohio, and at Charlottesville, Va.

The period of observation and analysis of the fruit samples was considerably extended beyond that previously reported and more complete analyses were made so as to secure additional data covering several important questions, such as the presence of other acids than tartaric and the changes in the ratio of combined and free tartaric acid. The study of the increase of sugar content and the changes in total acid content remain, however, as heretofore, the prime object of the investigation.

Study of the fundamental changes which occur during the ripening of grapes is of importance in the determination of the normal compo$12253^{\circ}-$ Bull. $335-16-1$ 
sition of grape products, and it would appear that the data secured should have practical value to growers who wish to secure the highest quality of fruit, therefore the analytical results are presented quite fully.

\section{CHANGES IN THE CHEMICAL COMPOSITION OF GRAPES DURING THE RIPENING PERIOD.}

The ripeness of the grape should not be judged merely by its color, for many varieties color long before they are fully ripe. Ripeness can be properly determined only when both chemical composition and physiological condition are considered. Many of the varieties of grapes derived from native American species at present commercially grown show a rather high acidity. In such grapes the qualities desired are the highest content of sugar and the lowest content of acid which can be secured without deterioration of the marketable condition of the crop. Some exceptions to this statement may be noted, as, for instance, the Delaware, which, when fully ripe, shows an acidsugar ratio too wide for dry wine manufacture.

In the ripening of grapes the increase of sugar and the elimination of acid are dependent upon many factors, such as climatic and soil conditions, the vigor of the plant, the site, pruning and training, and species and variety characteristics. With certain reservations, sugar should increase and acid diminish as long as the leaves function properly. This, however, is not always the case, for as soon as the pedicels-the small stems which carry the berries-begin to wither, the fruit is gradually cut off from further influence of the growth processes taking place in the plant, and its sugar content may remain fairly constant for some time. It may appear to increase by reason of evaporation of water from the berries, or in certain cases may seem to be reduced by changes induced by the respiratory processes of the fruit. The acid content is notably affected by respiration, especially if malic acid is present in any quantity. ${ }^{1}$

The total sugar and acid content are not the sole factors of importance in determining the acceptability of the fruit for manufacturing purposes, because the total acid-reacting substances are composed of several substances, among which the malic acid is at times quite as important as the tartaric acid. The content of malic acid is of importance, because this acid is to a considerable extent eliminated by oxidation through respiratory processes during the development of the fruit. ${ }^{2}$ As far as this process occurs it causes a positive lowering of the acid content of the juice. In wine making whatever portion of the malic acid remains free and goes into the young wine

1 Babo und Mach, Weinbau, 3d ed., 1909, 1: 117, 157-159; Ibid, Kellerwirtschaft, 4th ed., 1910, 2: 12, 13, $31,162$.

2 Ibid. 
can be largely changed by after-fermentation into lactic acid and carbon dioxid, ${ }^{1}$ thus still further lowering the acid content of the final product. This latter change in the malic acid can not, however, occur in juices that are used in unfermented condition, as bottled grape juices.

The occurrence of malic acid in the grape is very well known, yet it is difficult to determine the acid as such by the methods available in this laboratory; hence the acid substances here discussed as malic acid were not estimated by direct determination. These substances are in fact the fixed acids other than tartaric, but it is known that of these only malic acid ${ }^{2}$ occurs in important quantities.

The total acidity of the fruit is also very sensibly lowered some seasons through the disappearance of free tartaric acid during ripening. It appears from our results that free tartaric acid in many cases entirely disappears in the ripe fruit, especially from those varieties with dark-colored juice. In some varieties with lightcolored juice, like Catawba, the disappearance of free tartaric acid does not seem so complete, especially when the fruit ripens late.

The disappearance of free tartaric acid ${ }^{3}$ as the fruit matures is primarily due to the influx, into the developing fruit, of potassium, which combines with the free tartaric acid to form cream of tartar, the insoluble acid tartrate of potassium. This compound is present in all grape juices and its titratable acidity is but one-half that of the free tartaric acid before combination with the potassium, hence those conditions which encourage the formation of this acid salt sensibly reduce the acidity of the juice of the fruit. Other bases, such as lime and magnesia, also enter into combination with tartaric acid to form the alkaline-earth tartrates; but these salts occur only in slight quantities, and their presence does not materially affect the total acidity from the manufacturing standpoint. The formation of crystals of cream of tartar in the fruit, and the fact that these crystals occur in the pressed residue of freshly-crushed grapes, has been determined by the authors, ${ }^{4}$ but these phenomena require further study before their effect upon total acidity can be stated. The precipitation of this salt of tartaric acid, in whatever manner it may occur, has a marked effect upon the final acidity of food products made from grape juice. Thus a freshly-pressed grape juice or young wine will ordinarily show a decided precipitation of tartar or argol within a few months.

After the disappearance of all free tartaric acid any further influx of potassium or of other bases will result in a union with the malic

1 Külisch, Weinverbesserung, 3d ed., 1909, p. 19.

2 Babo und Mach, Kellerwirtschaft, 4th ed., 2: 12, 162-163.

3 Babo und Mach, Weinbau, 3d ed., 1909, 1: (1) 159-161, tables; Ibid, Kellerwirtschaft, 4th ed., 1910, 2: 13-14; Koenig, Nahrungs und Genussmittel, 4th ed., 1903, p. 1174.

4 J. Agr. Res., 1913, 1: 513. 
acid to form malates of potassium, calcium, or magnesium. The formation of these salts would still further reduce the acidity of the juice.

There is a further consideration which enters into the relative acid content of green and ripe fruit-that of the dilution of the acidity by an increase of the sugar and water content. An attempt to determine the extent to which this change affects the percentage of acid content was undertaken in 1912 and is treated in a section of this report.

It appears, then, that there are a number of changes in the composition of the fruit during its development and ripening which tend to lower the acid content. Therefore, grapes which originally contained a high total acidity might in many cases mature so as to reduce the final acid content of products made from them. The prime points of consideration for wine making are that the fruit should be well ripened, so that all of the combinations of the bases with the acids which are possible may be carried to completion and that malic acid may be eliminated by growth processes to the fullest extent practicable. Then the cream of tartar in the expressed juice, whether it be used for unfermented fruit juice or for wine, should be precipitated as perfectly as possible. If malic acid is present in any quantity in wine it will be largely changed by after-fermentation into lactic acid, if proper conditions are observed.

Then a grape may be said, in a manufacturing sense, to be ready to harvest at that period in its development when the sugar content and the acid elements have reached the most favorable state (considering the purpose for which it is intended) that is possible for the variety in the particular season, location, and other prevailing conditions.

\section{SOURCES AND PREPARATION OF SAMPLES.}

During the years 1911 and 1912 a certain number of plants of each variety investigated were reserved for the samples desired. These plants were selected with a view of guarding a quantity of average fruit so that the sampling might be done in a manner to secure typical material. The work of this laboratory on grape samples during the past four years has shown that it is not possible to select two samples of fruit at the same time which shall be exact duplicates. It is also true that one can not select samples from the same vines at different dates which will give results entirely logical in the sequence of the changing constituents. The analyses herein reported show the effect of these variations in sample, but these are not such as to confuse the results.

The 1911 samples of Catawba, Delaware, Ives, and Norton, examined at Sandusky, Ohio, were taken from a vineyard at Venice, about 3 miles west of Sandusky. The soil is heavy black loam over- 
lying limestone. The land is flat and only a few hundred yards from the shore of Lake Erie. The 1911 samples of Clinton were taken from a neighboring vineyard on similar soil. These samples were collected in every instance by J. R. Eoff. who was in charge of the chemical examinations at Sandusky.

The 1911 samples of Concord, Delaware, and Norton at Charlottesville, Va., were taken from a vineyard of which the soil is the characteristic Piedmont red clay, lying on a slope just below an outcrop of gray sandstone. The Cynthiana samples were taken from another vineyard situated on soil of like character. These samples were taken in every instance by William B. Alwood or B. G. Hartmann.

During 1912 fewer varieties were examined than previously, but the amount of work done was extended to cover points not before investigated. At Sandusky only Concord and Catawba were examined, and these were obtained from the vineyard first described. At Charlottesville, Concord and Delaware were examined, both from the vineyard which had supplied samples of these varieties the previous year.

For all examinations of whatever nature about 5 pounds of fruit were selected in the vineyard and the bunches were placed in a small fruit basket and stored uncovered in the cellar of the laboratory for 18 to 24 hours at a temperature of about $60^{\circ} \mathrm{F}$. The purpose of holding the fruit in the cellar was to bring all samples to as nearly as possible the same temperature before crushing, so that the results for creain of tartar should not be affected by reason of the variation in its solubility at different temperatures.

The fruit used for juice samples was brought from the cellar and crushed at once by hand in porcelain-lined vessels. About 2 pounds of unstemmed fruit were used and care was observed to take average quality as to ripeness. The berries were carefully pulped with the fingers until well broken up, then the juice was expressed through a double thickness of cheesecloth, working the pulp into a ball in the cloth and applying such pressure as experience has shown will ordinarily extract the juice as efficiently as when freshly pulped fruit is pressed on a power press at 1,500 pounds direct pressure. The juice recovered was strained by filtering through cotton, and from this portion the chemical sample was taken. A Brix reading was then made at $20^{\circ} \mathrm{C}$. on the fresh juice. Then $250 \mathrm{cc}$ of the sample, the quantity desired for analysis, were measured and diluted with an equal volume of distilled water, thus giving $500 \mathrm{cc}$. This diluted sample was filtered through paper and a $20 \mathrm{cc}$ portion titrated for total acid; the specific gravity was determined at once in a pycnometer. During 1912 the specific-gravity determinations were made in a pycnometer on the undiluted juice. The further determi- 
nations were made as far as possible on the same day, or at least the manipulation was carried to a point where any change in composition would not affect the determination. All the determinations were completed within 36 hours after crushing the fruit.

Diluting the samples keeps the juice more nearly normal, preventing precipitation of tartar, which may occur if the sample should stand for some hours. The diluted sample can be filtered much more readily than the undiluted juice, and in case of colored juices a clearer end point is obtained when the sample is titrated for acidity.

While the analyses made in 1912 were confined to three varieties, the work was extended to include complete analyses of the fruit of two varieties, as well as the analyses of the juice samples as heretofore made. First, an analysis of the juice sample was made in the manner detailed for 1911, and the results for 1912 are in all respects comparable with the data for that year, save that the total tartaric acid for 1912 was obtained by the method of half neutralization proposed by Hartmann and Eoff. ${ }^{1}$

It is evident that the analysis of a juice sample does not furnish final data on the composition of the entire fruit, because it is impossible to secure, by crushing and pressing a sample of the fruit, all of the constituents of the berries. This method secures only such as are in solution in the juice sample recovered. While the results for many constituents when the juice and whole-fruit sample are compared are somewhat similar, there are some important variations.

For the sample for whole fruit analyses in 1912, taken at the same time and from the same fruit selected for the juice sample, the berries were carefully clipped with sharp scissors from the stems at the junction of the fruit with the pedicels, care being taken not to break the skin of the fruit. A sample of 800 to 1,000 grams was prepared in this manner. The berries were held in a large piece of cheesecloth and rolled to and fro until they were thoroughly mixed, then from different portions of the mass two samples of 100 grams each were taken for duplicate determinations of the organic constituents, and three samples of 100 berries each for triplicate weighings and measurements of volume of the fruit. The several samples required for burning direct to secure the ash samples were also taken at this time.

The samples for the organic determinations were exhausted in distilled water as follows: Each was placed in a cheese-cloth square and tied firmly with twine, so that the fruit was confined in a ball. These were suspended in 500 cc beakers containing about $200 \mathrm{cc}$ of distilled water, placed over a flame, and kept constantly at boiling temperature. After 10 to 20 minutes the water containing the solution extracted from the fruit was removed to a large porcelain

1 U. S. Dept. Agr., Bur. Chem., Bul. 162, pp. 71-77. 
evaporating dish and replaced with hot distilled water. This exhaustion was repeated five or six times and the solution collected in the porcelain dish. When the extraction seemed complete, cold distilled water was added to the beaker. The pulp in the cloth was then carefully worked and pressed with the fingers to extract the remainder of the soluble constituents, which was added to the extract already collected. To determine whether the exhaustion was complete the pomace in the cloth was again treated with boiling water and a 10 cc portion titrated with tenth-normal sodium hydroxid, using phenolphthalein as indicator. If not more than $0.5 \mathrm{cc}$ of tenth-normal sodium hydroxid were required to neutralize the portion taken, exhaustion was considered complete. If the material still showed appreciable acid the extraction with water was continued until complete.

The solution collected from the successive boilings, after being kept on a water bath until the volume was sufficiently reduced, was transferred to a 500 cc graduated flask. The porcelain dish was carefully rubbed with a policeman and rinsed with hot water until all the extractive matter was recovered. The solution was cooled to room temperature and made up to $500 \mathrm{cc}$, and from this sample all the organic determinations were made. The fruit samples were treated in duplicate by this method and the results checked satisfactorily. The average result of these two determinations, in percentage of the weighed fruit sample, is given in Table 6 .

In order to determine more accurately the inorganic constituents, such as phosphoric acid, chlorin, potassium oxid, sodium oxid, calcium oxid, and magnesium oxid, weighed portions of the same fruit sample were ashed direct for these determinations. An attempt was made to use the solution extract for the determination of chlorin, but it was found by check determinations that this solution gave a large excess of chlorin, indicating that chlorin was probably introduced in some manner during the preparation of the solution. The fruit for these determinations was ashed in platinum dishes in the usual manner, 50 to 80 gram samples being used. The results are given in percentage of the weighed sample.

\section{METHODS OF ANALYSIS.}

The official methods for wine (Bureau of Chemistry Bulletin 107, Revised) were followed in the work done during 1911, save for cream of tartar, free tartaric acid, tartaric acid to alkaline earths, and for the item reported as fixed acid other than tartaric. For determining these substances; except the last named, the revised methods given (Bureau of Chemistry Bulletin 162, pages 71 to 77) were followed, and in the results reported for 1912 the total tartaric acid was determined by the revised method given in this bulletin. These 
methods have been carefully checked in this laboratory and at the Bureau of Chemistry and found to give more reliable results than the methods given in Bureau of Chemistry Bulletin 107, Revised. For the items reported as "Fixed acid other than tartaric," the following formula was used: Total acid as tartaric-[(total alkalinity $\times 0.0075)+$ free tartaric acid] $=$ fixed acid ather than tartaric expressed as tartaric. This result is practically the same as the "Sauerrest" of the German chemists. ${ }^{1}$

This formula gives those acids present other than tartaric, but as it is known that almost the total quantity of these acids in the grape consists of malic acid, ${ }^{2}$ the result may be interpreted as this acid for the considerations involved in this report. To actually convert this result to malic acid, multiply the figures given in the table by 0.8934 . It was not possible, with the conditions under which this work was done, to determine the minute quantities of other acids present, such as succinic and glycolic acids.

The total acid percentage is practically the same in the green fruit of Concord in both juice and whole-fruit samples, and this relation continues so nearly throughout the entire period that either result may be taken as fairly expressing the content. The total acid is decidedly higher in the juice sample of green Catawba than in the whole fruit for the first three samples taken; then the acid content of both samples becomes about what may be expected of check samples.

The results for total tartaric acid in the juice and whole fruit are not so uniform as for total acid. Yet for the Concord samples, both at Sandusky and Charlottesville, there is a degree of uniformity which is striking, considering the difficulty of sampling which has been mentioned. The Catawba samples show much difference in the green fruit, but the later samples approach uniformity.

There is a striking dissimilarity in the percentage of tartaric acid for the Concord samples at Sandusky and Charlottesville throughout the period of investigation. Those taken at Sandusky show much less variation than the Charlottesville samples and the former show approximately the same amount at the close of the season as for the partly colored samples first taken, while the Charlottesville samples show a very marked decline in tartaric acid for both the juice and fruit samples. Further investigation of this point is necessary before offering any critical discussion.

It would appear that the crushed fruit invariably yields decidedly the greater part of the free tartaric acid content when pressed. The rapid diminution of the percentage of this acid as the fruit ripens is shown for both the juice and fruit samples. These results support 
our previous determinations and show that the Concord juice loses free tartaric acid more completely than the Catawba.

The results for cream of tartar show that in every instance save one the juice sample carries a smaller percentage of cream of tartar than the whole fruit. The one exception, No. 3588, is affected by an evident error and is excluded from consideration. The excess, in per cent, of cream of tartar in the whole fruit is sufficient to support a previous statement that this substance exists as crystals and that some of these are retained in the pulp when the fruit is pressed.

The constant increase of cream of tartar both in the juice and fruit samples follows naturally from the disappearance of free tartaric acid. The results for 1912 are in this respect more logical than those for 1911.

The data given under fixed acids other than tartaric are considered by the authors to be remarkably interesting. It is shown that the total content of tartaric acid remains nearly constant, especially when the whole fruit samples are compared, but these other acids, which we have considered as mostly malic, show such a steady and sharp decline that one is forced to accept conclusions derived from the data given in Table 5. The reduction in the percentage of acid under this head reaches two-thirds to three-fourths of the entire amount given for the first samples taken.

\section{ANALYTICAL RESULTS ON THE JUICE SAMPLES.}

\section{CROP OF 1911.}

In Table 1 the condition of the fruit on the vines at the time of sampling and the results of the analyses of samples both at the Sandusky and Charlottesville laboratories are given in detail. The period covered by the analyses at Sandusky was carried beyond the wine-ripe condition, except in the case of the Norton, which was destroyed by the berry moth $^{1}$ before it was fully ripe. This continuation of the analyses was for the purpose of following the changes that occur in the fruit even to the natural destruction of the crop. The high temperature of the fall season at Charlottesville is not favorable to holding samples at that point after they are fully ripe, hence the data for that locality cover only the period to full maturity.

1 Polychrosis viteana Clemens.

$12253^{\circ}-\mathrm{Bull} .335-16-2$ 


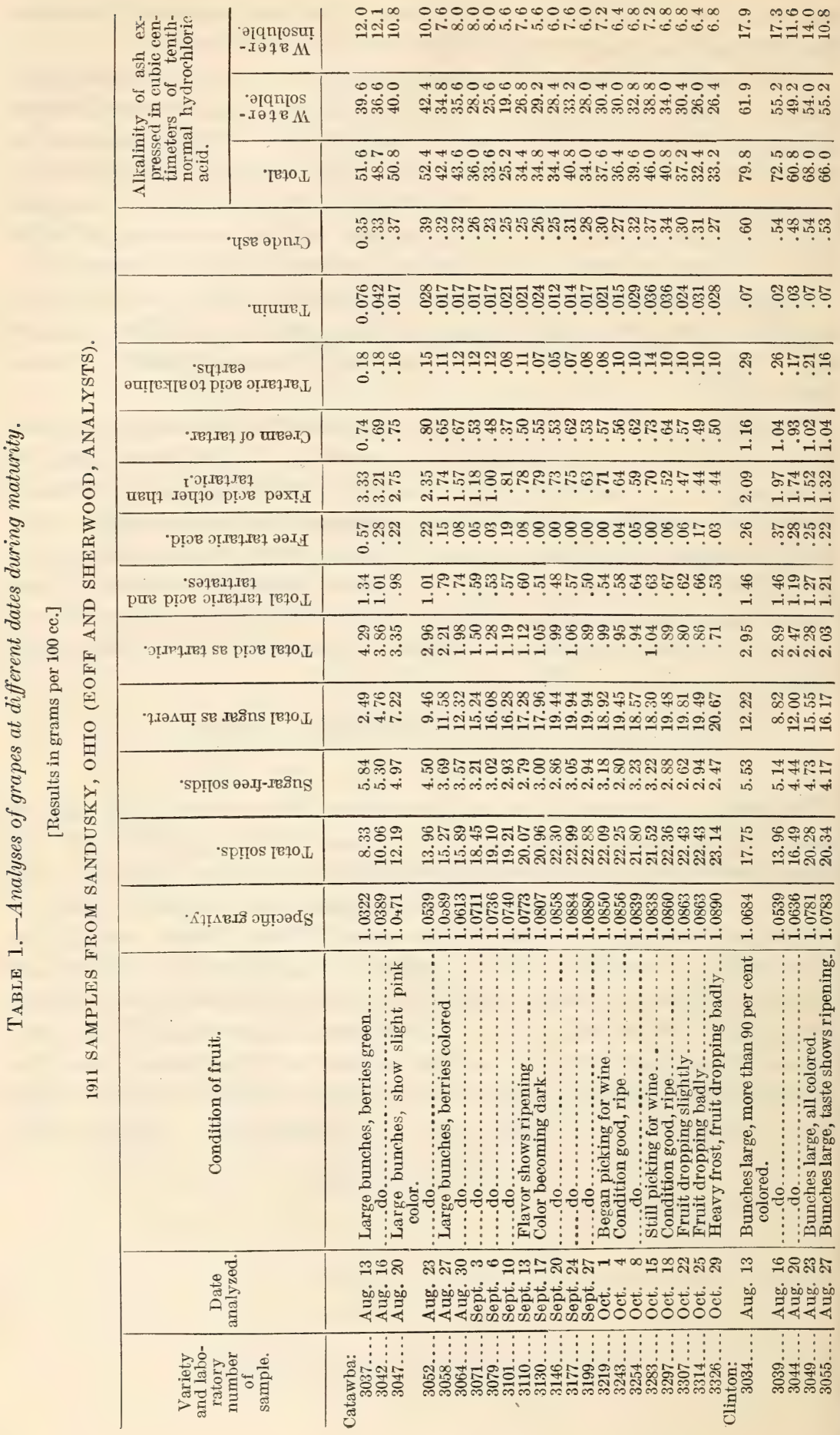


SUGAR AND ACID IN GRAPES DURING RIPENING.

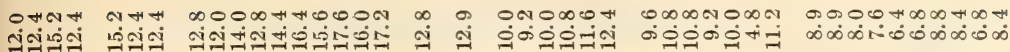

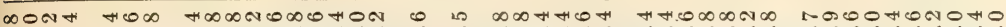

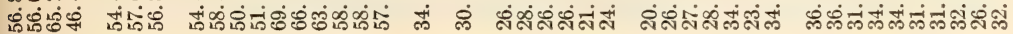

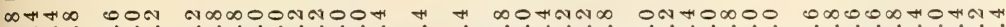

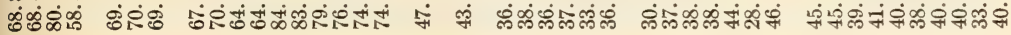

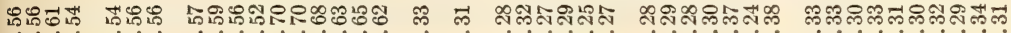

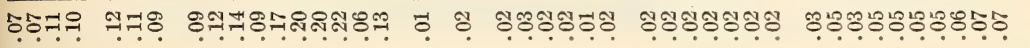

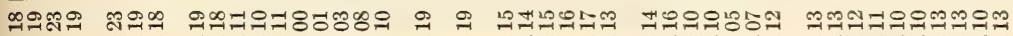

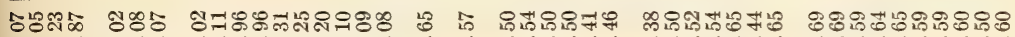
-i-i

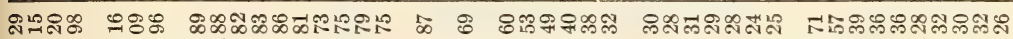
ini

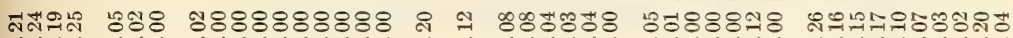

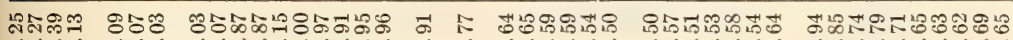

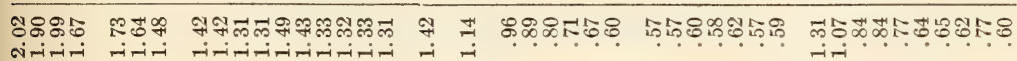

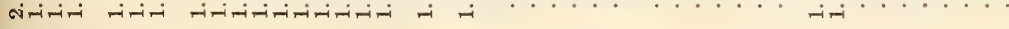

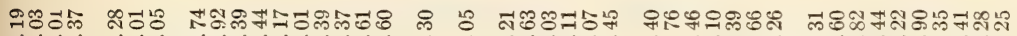

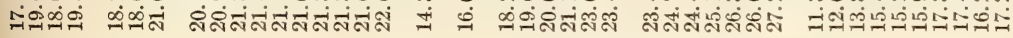

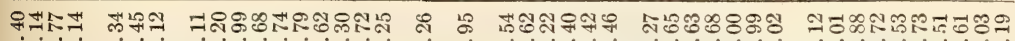

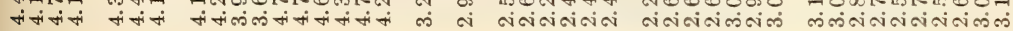

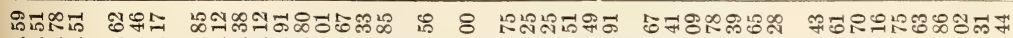

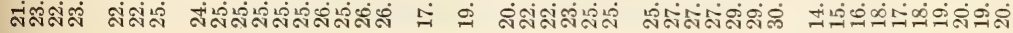

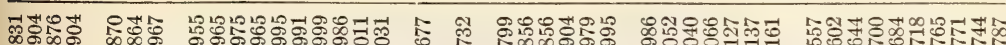

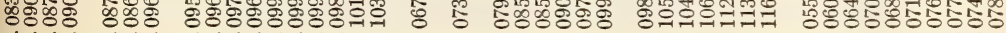

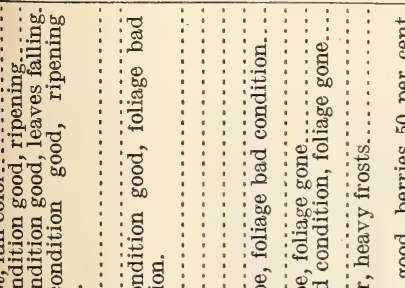

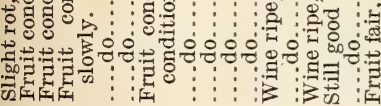

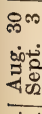
in .

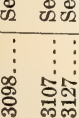

\section{西}




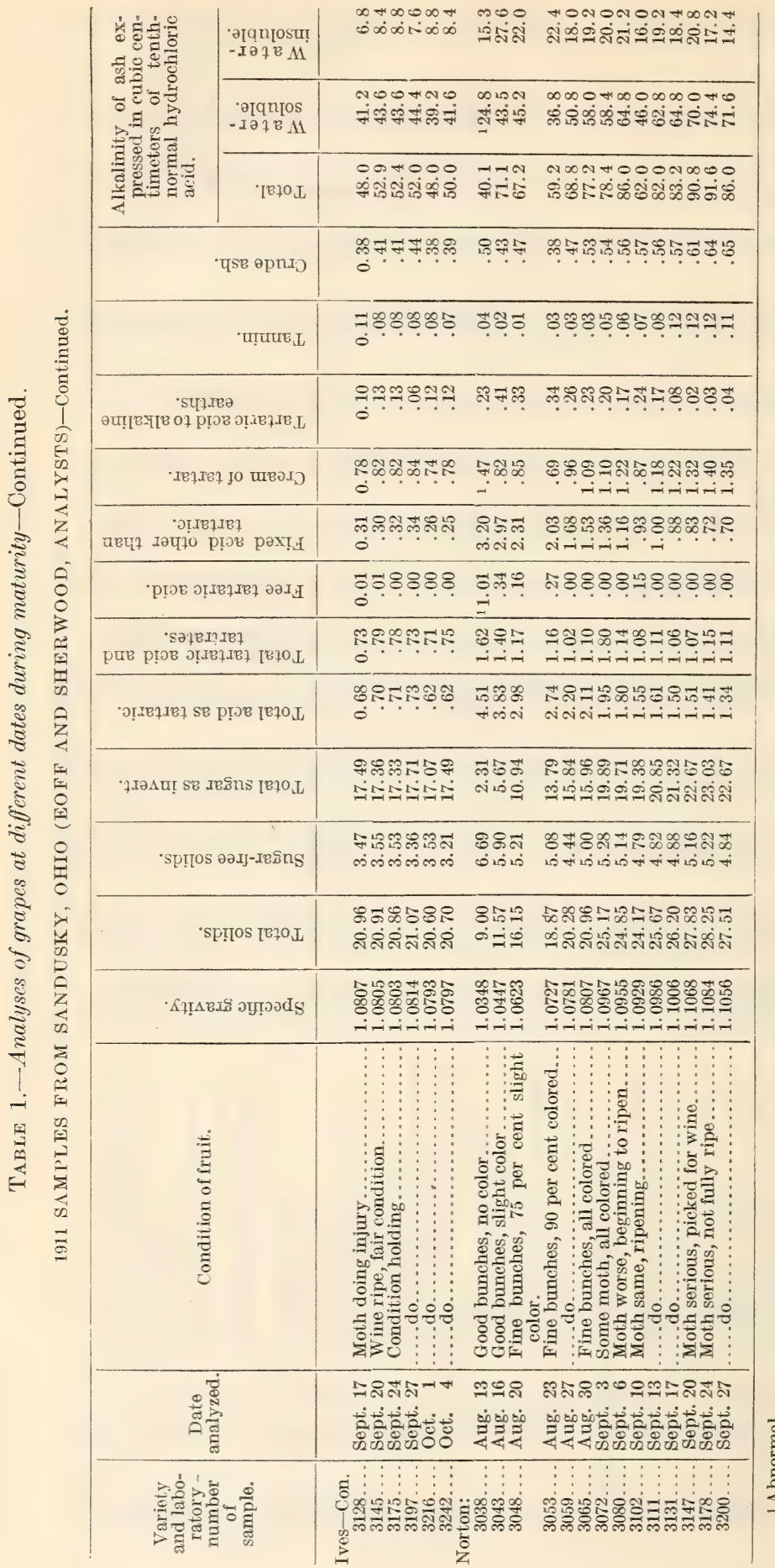




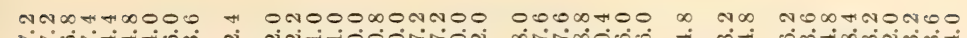

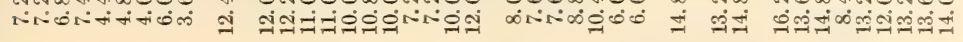

mon

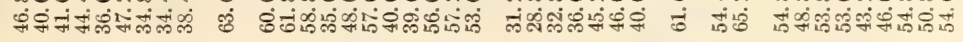

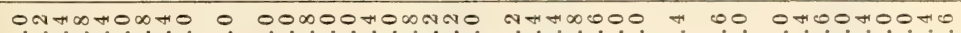

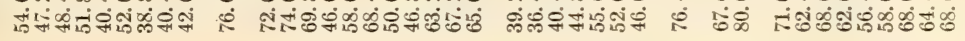

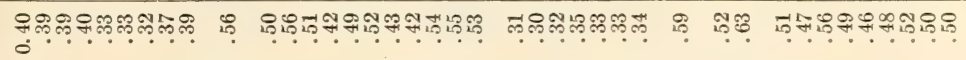

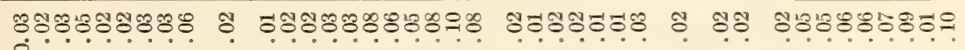

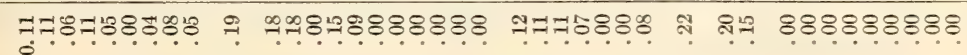

\begin{tabular}{|c|c|c|c|c|c|c|}
\hline 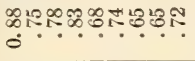 & ๙ุ & 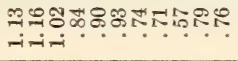 & 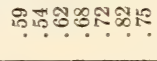 & $\stackrel{\bullet}{-}$ & 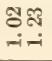 & 象 \\
\hline 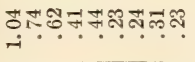 & $\begin{array}{l}\infty \\
\infty \\
\infty\end{array}$ & ๓̊. & & & & $\forall \infty$ \\
\hline 88 & 8 & 58 & 8 & ชิ & & $8 \%$ \\
\hline 象 & $\stackrel{\text { ลิ }}{\sim}$ & : & $\because \%$ & $\stackrel{ \pm}{-}$ & $\begin{array}{c}8 m \\
-i=1\end{array}$ & . \\
\hline 结 & $\begin{array}{l}\overrightarrow{\text { m }} \\
\text { क }\end{array}$ & -80010 & กै० & के & จ่ง & i- \\
\hline
\end{tabular}

స艹

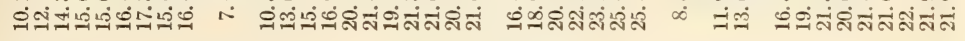

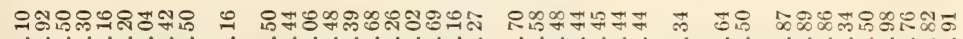

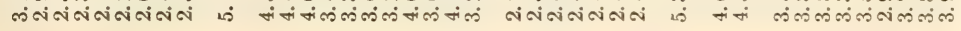

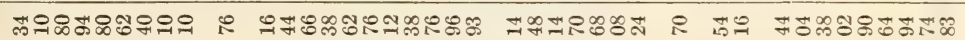

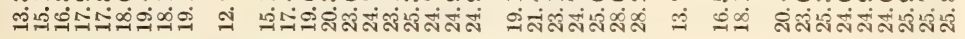

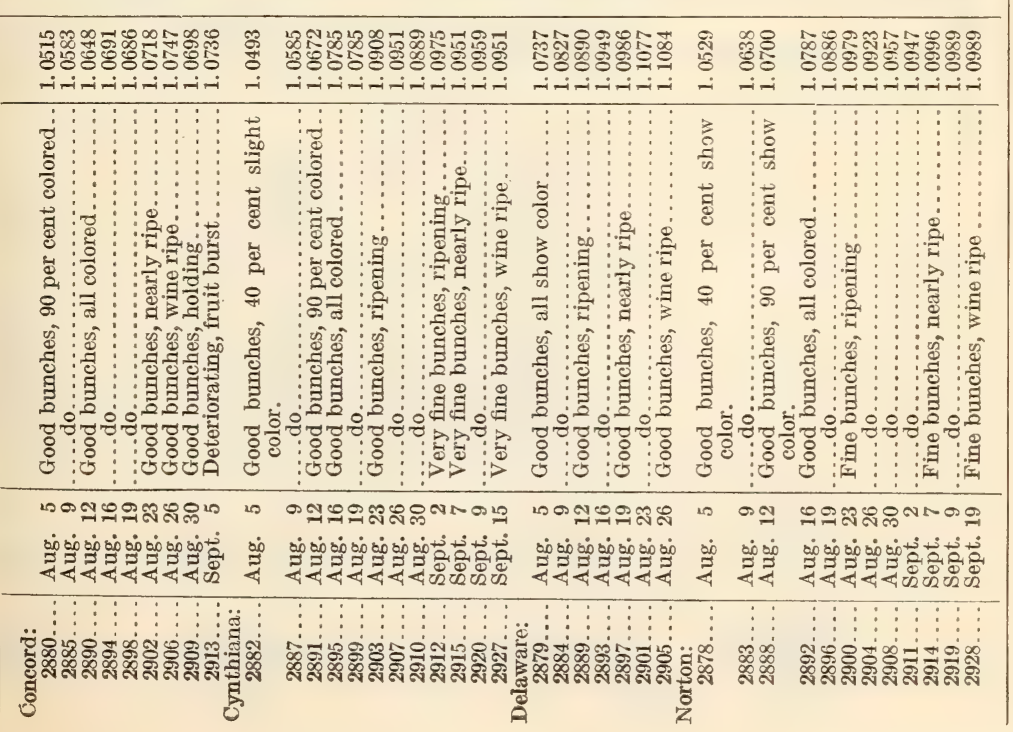




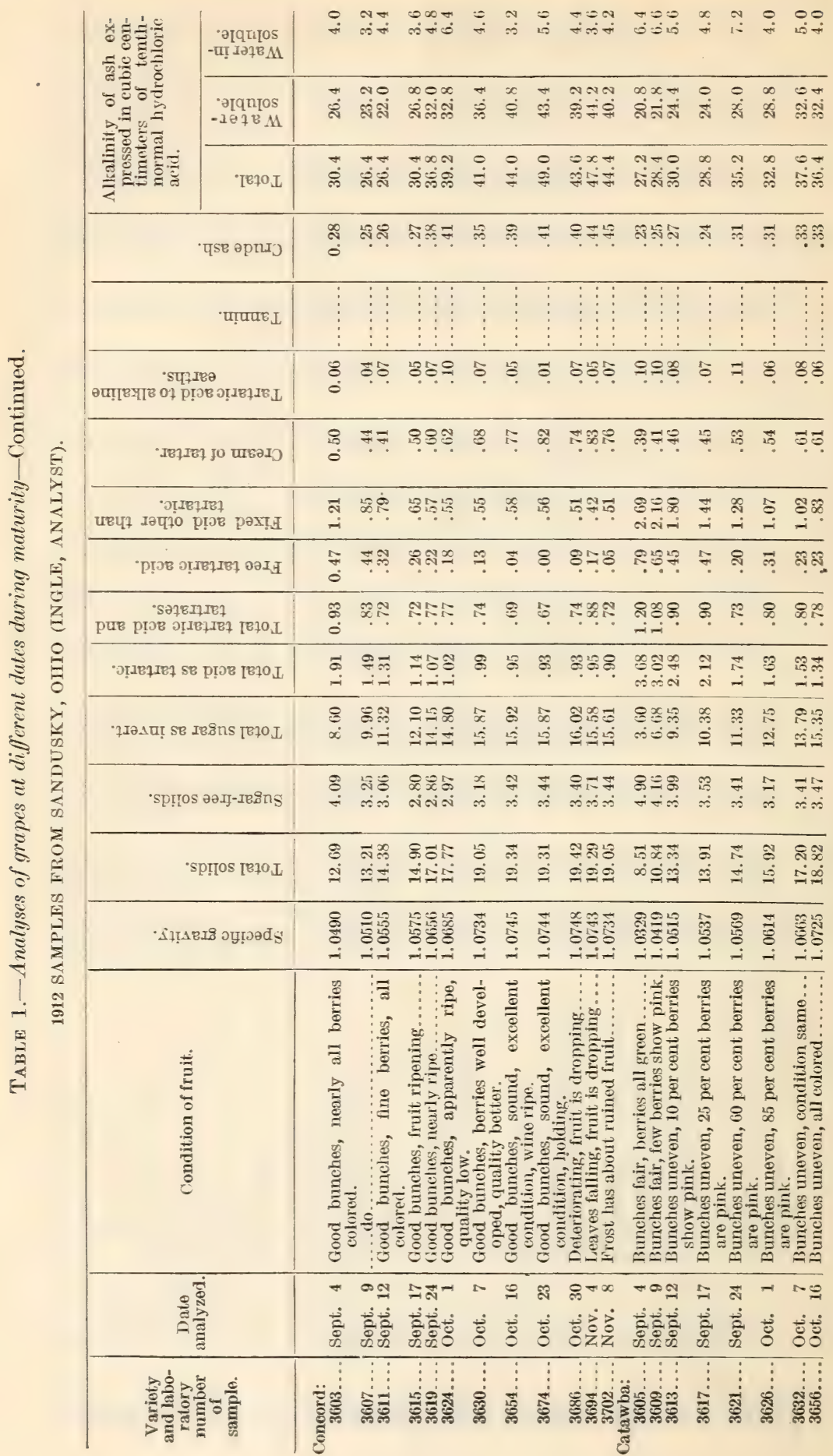




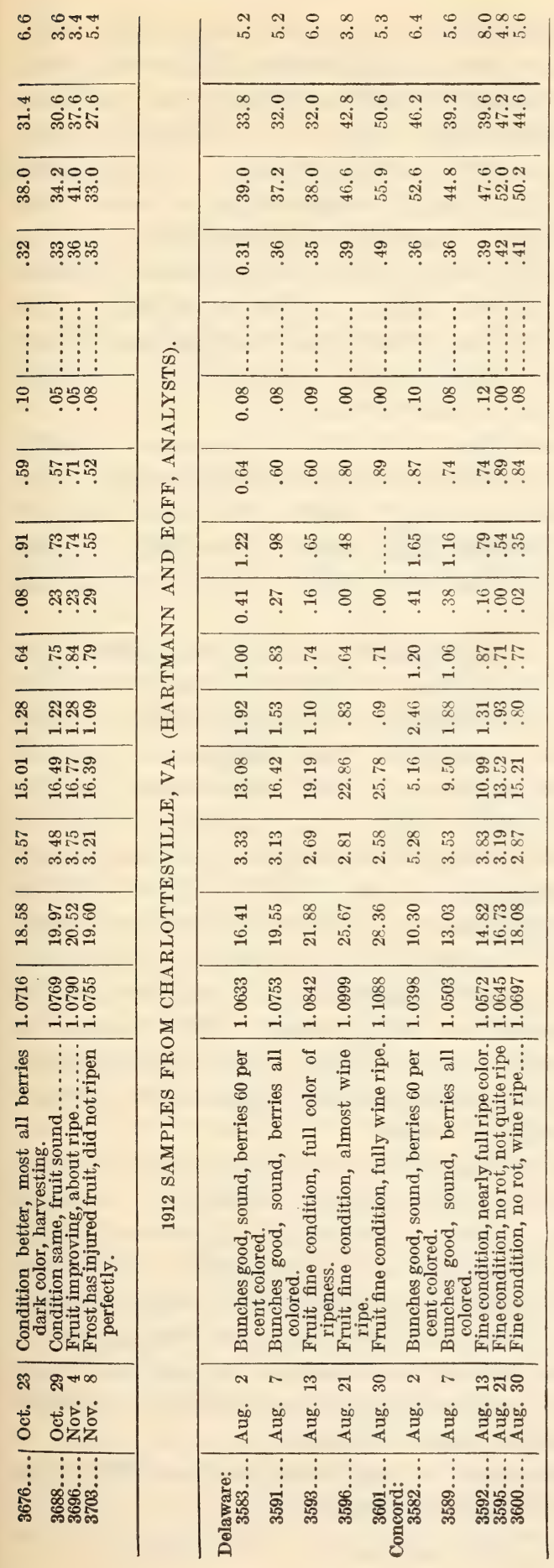


Particular attention is called to the data on sugar and acids. The Catawba crop studied in 1911 was harrested October 1 to 4, and though certain plants were held and sampling was continued 25 days longer, the results show only a gain of 1.22 grams of sugar and the loss of $0.24 \mathrm{gram}$ of acid in $100 \mathrm{cc}$ of juice. The apparent increase of sugar was doubtless due to evaporation of water from the berries and the loss of acid is possibly accounted for in the loss of malic acid. This would probably hare disappeared in wine fermentation, ${ }^{1}$ giving practically the same or a lower result than that recorded for the last sample. It is certain that nothing would have been gained for commercial purposes by holding this particular crop on the rine after the date it was harvested.

It is not to be understood that the dates of full-crop ripeness giren in the tables apply to all the vineyards of the Sandusky district. On the contrary, these dates apply only to the crops sampled. The season for Catawba in the Sandusky district lasts fully 3 weeks and the ripening of other- varieties extends over a considerable period, varying with location.

Clinton was sampled for 21 days after the crop was picked, but shows only an increase of 1.43 grams of sugar and a loss of 0.18 gram of acid. This rariety lost most of its foliage before the fruit was picked on October 7 and 8 and the later samples were picked from rines practically bare of leares. This undoubtedly had an influence on the high acid shown. In fact, this crop of Clinton shows the maximum acid at ripening of all the crops of this variety examined at Sandusky during the season of 1911. The fact that this rariety showed such high content of both malic acid and cream of tartar at ripening should be noted in this connection, because the presence of those elements greatly assists in the reduction of the acid of the finished products from this rariety. This occurs by precipitation of the crude tartar both in grape juices and wines and by destruction of malic acid with the formation of lactic acid through bacterial fermentation ${ }^{2}$ in case of wines.

The Delaware samples at Sandusky show the most notable increase of sugar after the date the crop was marked wine-ripe. However important it might appear to be to secure this increase of nearly 3 grams of sugar in $100 \mathrm{cc}$ of juice, it is not practicable to hold this crop so late because of the injury to the fruit from birds, insects, and rarious other causes. The acid reduction was inappreciable, but as a matter of fact this variety has scarcely enough acid when it is fully ripe for the best results in dry-wine making. Note the unusually wide total acid-sugar ratio in Table 2.

Ires, though held on the vine 14 days after marked fully ripe, showed rery slight changes in sugar and acid. 
The Norton samples were unfortunately destroyed by the berry moth before fully ripe, but the total sugar shown in this variety at Sandusky is remarkable, considering that it is distinctly a Southern grape. Possibly with extra effort it might be matured in the Sandusky district so as to show a lower acid content than it usually does.

The Concord grape samples at Charlottesville showed but small increase of sugar after they were fully colored. The season was very hot and dry and the fruit ripened quickly, then deteriorated rapidly, as shown by the analyses. This is the only variety sampled at Charlottesville after full maturity. The fruit burst and was badly attacked by birds and insects, hence the later samples were not normal.

Cynthiana was 30 days in reaching full maturity after the berries were colored. The increase of sugar during this long period was not really marked. The results show only about 40 per cent more sugar in the last than in the first sample; but the loss in acid in $100 \mathrm{cc}$ of juice was 63 per cent. This gave a rich juice with a very moderate acid content-only 0.75 gram in $100 \mathrm{cc}$.

Delaware was sampled at Charlottesville for 21 days after the berries were colored until full ripeness. The increase of sugar was 57 per cent and the drop in acid slight. The final sugar content is too high for the acid strength, as is also noted for the Sandusky samples. This fruit can not well be held at Charlottesville for study after full maturity. It would, however, most likely show final sugar equal to the Sandusky samples. (Note that the acid-sugar ratio for Delaware at wine-ripeness is practically the same for both districts.)

Norton was sampled for 34 days at Charlottesville, after it was fully colored but before it was fully ripe, with an increase of only 5.35 grams of sugar in $100 \mathrm{cc}$ of juice; but the decrease in acidity of 1.33 grams is the greatest noted for any variety from the period of full coloring until ripe. The final acid of 0.80 gram in 100 ce shown by this crop is remarkably favorable for this variety.

It is a noteworthy point that free tartaric acid practically disappeared from the grapes having dark-colored juice, both at Sandusky and at Charlottesville, some time previous to maturity. The very large amount of fixed acids other than tartaric (which are treated in this discussion as malic acid), shown in the green Catawba, Clinton, Cynthiana, and Norton, is interesting. None of the other varieties nearly equal these four in this regard. The data show that the loss of acid during the maturity of the fruit is very largely due to the changing of the malic acid, but there is in every instance a greater loss of total acid than of malic. This is in accordance with what should normally occur through the combination of free tartaric with potassium and other bases forming cream of tartar and 
alkaline-earth tartrates. So long as free tartaric acid is present the loss of malic acid is accounted for by the vital processes of the plant, but as soon as there is no longer free tartaric acid present, malic acid will combine with potassium and other bases which may continue to enter the fruit by influx of sap. It would appear that though the fruit was held on the vines at Sandusky until long overripe, the sugar apparently increased to the last and the malic acid decreased.

The total acidity of the first sample of Catawba is nearly twice the sugar content. Norton also shows the same relation, but all the other varieties show a much higher ratio of sugar to acid in the first samples. These two varieties develop their sugar content rapidly during the later period of growth and decline in acid content with marked rapidity. Note in this connection the ratio of loss of acid to increase of sugar in Table 2. The acid content of the Catawba sample when harvested was only 22 per cent of the acid shown in the first sample, and the last frosted sample of Catawba showed only about one-sixth of the acid contained in the first sample. Though the Norton crop at Sandusky did not fully ripen, the acid of the last sample was not quite 30 per cent of the first sample. The sugar of the last sample of these two varieties at Sandusky was approximately ten times that of the first sample. Clinton and Cynthiana do not show anything like such extremes, though varieties of about the same season and composition when ripe. Delaware, Ives, and Concord do not show these striking contrasts.

The results for cream of tartar are somewhat abnormal and should be checked by further complete analyses of the fresh fruit. It would appear that cream of tartar should increase in the fruit of the grape until fully ripe, or, more correctly, until all free tartaric acid disappears, but the evidence on this subject, to which there was access, is not conclusive. Certainly the results of the analyses of fresh juice thus far made do not fully support this presumption. Only the samples of Norton taken at Sandusky show a notable increase of cream of tartar at maturity. Ives and Clinton show also a slight increase. Delaware at Charlottesville shows a slight increase, but all other varieties show a decline of this substance. These results raise the question as to whether the cream of tartar can be wholly recovered by the method of extracting the juice followed in this laboratory. It is undoubtedly true that this substance is deposited as crystals when the juice is fully saturated, and especially will this be more pronounced as the acid content declines and the sugar content increases. The temperature of the sample might affect the results to a slight degree because of the varying solubility of cream of tartar at different temperatures. 
Some interesting points are brought out by comparing the sugar and acid content from the date when all the berries were colored until fully ripe. The note "Berries, colored" is necessarily somewhat arbitrary, because the coloring of these varieties is not at all alike; but we have used it in the general sense understood by the grape growers. These comparisons are presented in Table 2:

TABLE 2.-Increase of sugar and decrease of acid for certain periods, 1911.

[Results in grams per 100 ce.]

SANDUSKY, OHIO.

\begin{tabular}{|c|c|c|c|c|c|c|c|c|}
\hline Variety and date. & $\begin{array}{l}\text { Condition of } \\
\text { berries. }\end{array}$ & $\begin{array}{c}\text { Days } \\
\text { elapsed. }\end{array}$ & $\begin{array}{l}\text { Total } \\
\text { sugar. }\end{array}$ & $\begin{array}{l}\text { Gain of } \\
\text { sugar. }\end{array}$ & $\begin{array}{l}\text { Total } \\
\text { acid. }\end{array}$ & $\begin{array}{l}\text { I.oss of } \\
\text { acid. }\end{array}$ & $\begin{array}{c}\text { Ratioloss } \\
\text { of acid to } \\
\text { gain of } \\
\text { sugar. }\end{array}$ & $\begin{array}{c}\text { Acid- } \\
\text { sugar } \\
\text { ratio in } \\
\text { ripe fruit. }\end{array}$ \\
\hline $\begin{array}{l}\text { Catawba: } \\
\quad \text { Aug. } 27 \ldots . \\
\text { Oct. } 4 \ldots \ldots\end{array}$ & $\begin{array}{l}\text { Berries, colored.. } \\
\text { Wine-ripe....... }\end{array}$ & 38 & $\begin{array}{l}11.58 \\
19.45\end{array}$ & 7.87 & $\left\{\begin{array}{r}2.21 \\
.95\end{array}\right.$ & 1.26 & 1: 6.2 & $1: 20.5$ \\
\hline $\begin{array}{l}\text { Clinton: } \\
\quad \text { Aug. } 23 \ldots . . \\
\text { Oct. } 8 \ldots . .\end{array}$ & $\begin{array}{l}\text { Berries, colored.. } \\
\text { Wine-ripe....... }\end{array}$ & 46 & $\begin{array}{l}15.55 \\
21.17\end{array}$ & ن. 62 & $\left\{\begin{array}{l}2.28 \\
1.49\end{array}\right.$ & .79 & $1: 7.1$ & $1: 14.2$ \\
\hline $\begin{array}{l}\text { Delaware: } \\
\text { Aug. } 20 \ldots \ldots . . . . \\
\text { Sept. 17.......... }\end{array}$ & $\begin{array}{l}\text { Berries, colored.. } \\
\text { Wine-ripe....... }\end{array}$ & 28 & $\begin{array}{l}19.21 \\
24.46\end{array}$ & \} 6.25 & $\left\{\begin{array}{l}.96 \\
.60\end{array}\right.$ & .36 & $1: 17.4$ & $1: 40.8$ \\
\hline $\begin{array}{l}\text { Ives: } \\
\quad \text { Aug. } 13 \ldots \ldots \ldots \ldots \\
\text { Sept. } 20 \ldots \ldots \ldots \ldots\end{array}$ & $\begin{array}{l}\text { Berries, colored.. } \\
\text { Wine-ripe....... }\end{array}$ & 38 & $\begin{array}{l}11.31 \\
17.36\end{array}$ & 6.05 & $\left\{\begin{array}{r}1.31 \\
.70\end{array}\right.$ & .61 & 1: 9.9 & $1: 24.8$ \\
\hline $\begin{array}{l}\text { Norton: } \\
\text { Aug. } 30 \ldots \\
\text { Sept. } 27 . . .\end{array}$ & $\begin{array}{l}\text { Berries, colored.. } \\
\text { Last sample } 1 . .\end{array}$ & 28 & $\begin{array}{l}15.96 \\
22.67\end{array}$ & 6.71 & $\left\{\begin{array}{l}2.11 \\
1.34\end{array}\right.$ & .77 & $1: 8.7$ & $1: 16.9$ \\
\hline
\end{tabular}

CHARLOTTESVILLE, VA.

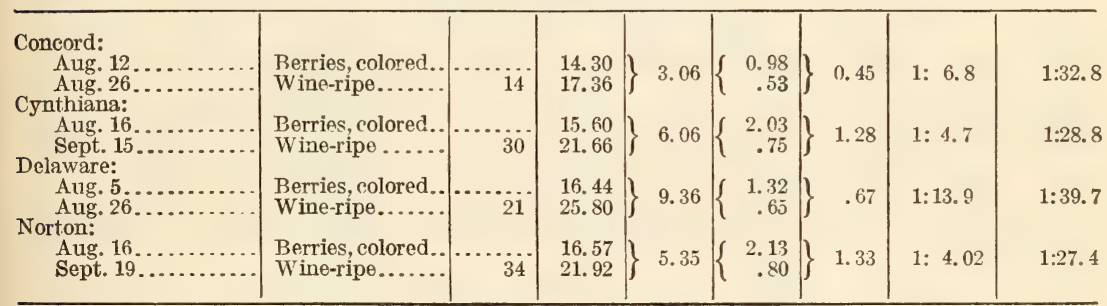

1 Fruit was not fully ripe.

The summary of the data given in Table 2, on changes in sugar and acid content of these varieties from the time the berries were colored until wine-ripe, show striking differences in the ratios, loss of acid to gain of sugar, and total acid to total sugar, at full ripeness. The greatest loss of acid to gain of sugar, hence the lowest ratio, is shown by Cynthiana and Norton at Charlottesville, and Catawba at Sandusky. The full data given in Table 1 show in detail the development of these varieties and that when ripe they gave an excellent juice for wine making. The ratio for these three varieties as to total acid and sugar when fully ripe show that the Catawba at Sandusky was not so well balanced in acid and sugar content as the Cynthiana 
and Norton at Charlottesville. The analyses of this Catawba crop, which was inferior to some others of the Sandusky district, show its high value for wine manufacture.

The extremely high ratio of gain in sugar to loss in acid shown by Delaware and the very wide ratio of total acid to sugar content in this variety bears out the previous statement that this grape is low in acid for commercial purposes. This grape would make a wine with an acid-alcohol ratio when finished of about 1 to 26 , whereas 1 to 20 is about the right ratio for a potable wine of this class.

\section{CROP OF 1912.}

The work on development of acid and sugar content in grapes was confined during 1912 to two varieties, Concord and Catawba, at Sandusky, and also to two varieties, Delaware and Concord, at Charlottesville. The full data on the juice samples are given in Table 1. A much more complete study of the composition of the whole fruit was undertaken than heretofore, with results as given in Table 6. This later work consisted of fairly complete organic and ash analyses of the whole fruit, whereas the work done heretofore was confined to the expressed juice.

All of the fruit used in 1912 was taken from vines reserved for this work and the sampling was done in every instance by the same persons as in 1911.

The work at Sandusky was begun several weeks later than in 1911, but the first samples were taken before the fruit was fully colored. The crop was late and Catawba developed unevenly and was not in prime condition at any time. In fact the Catawba crop used for this work failed to mature properly and did not fully ripen; 1912 was a poor crop year for all the late grapes in northern Ohio. At Charlottesville the fruit ripened promptly and was in excellent condition.

A comparison of the sugar and the acid elements in the composition of Catawba for the two years, 1911 and 1912, are presented in Table 3. The results for 1912 are taken from the date when the fruit was noted as showing pink color instead of fully colored, as in 1911. The coloring of this fruit in different years varies greatly, but the sugar and acid content indicates comparatively the same stage of ripeness when the first samples used in the comparison were taken. As the dates of sampling for the two years are not the same, two dates are given for each line in the date column at the left of the table. The first date in each case is the date of sampling for 1911 and the second for 1912. The comparison does not include all the analyses for 1911, but does give those which mark the several stages of maturity to the date when the crop was fully ripe, and the results are given for 1912 until the fruit was destroyed by frost. 
TABLE 3.-Comparison of sugar and acid elements in Catawba fruit, 1911-12.

\begin{tabular}{|c|c|c|c|c|c|c|c|c|c|c|c|c|c|}
\hline \multirow{2}{*}{\multicolumn{2}{|c|}{$\begin{array}{l}\text { Dates when } \\
\text { sampled. }\end{array}$}} & \multirow{2}{*}{\multicolumn{2}{|c|}{ Sugar. }} & \multirow{2}{*}{\multicolumn{2}{|c|}{ Total acid. }} & \multicolumn{4}{|c|}{ Tartaric acid. } & \multirow{2}{*}{\multicolumn{2}{|c|}{$\begin{array}{l}\text { Fixed acids } \\
\text { other than } \\
\text { tartaric. }\end{array}$}} & \multirow{2}{*}{\multicolumn{2}{|c|}{$\begin{array}{l}\text { Cream of } \\
\text { tartar. }\end{array}$}} \\
\hline & & & & & & \multicolumn{2}{|c|}{ Total. } & \multicolumn{2}{|c|}{ Free. } & & & & \\
\hline 1911 & 1912 & 1911 & 1912 & 1911 & 1912 & 1911 & 1912 & 1911 & 1912 & 1911 & 1912 & 1911 & 1912 \\
\hline Aug. 20 & Sept. 9 & 7.22 & 6.68 & 3.35 & 3.02 & 0.98 & 1.08 & 0.22 & 0.65 & 2.75 & 2.16 & 0.75 & \\
\hline Aug. 23 & Sept. 12 & 9.46 & 9.35 & 2.96 & 2.48 & 1.01 & .90 & .22 & .45 & 2.35 & 1.80 & .80 & \\
\hline Aug. 27 & Sept. 17 & 11.58 & 10.38 & 2. 21 & 2.12 & .79 & .90 & .15 & .47 & 1.74 & 1.44 & .65 & \\
\hline Aug. 30 & Sept. 24 & 12.32 & 11.33 & 1.98 & 1.74 & .74 & .73 & .08 & .20 & 1.57 & 128 & .67 & \\
\hline Sept. 3 & Oct. 1 & 15.24 & 12.75 & 1.50 & 1.63 & .59 & .80 & .05 & .31 & 1.18 & 1. 07 & .53 & \\
\hline Sept. 6 & Oct. 7 & 16.08 & 13.79 & 1.28 & 1.53 & .53 & .80 & .03 & .23 & 1.00 & 1.02 & .48 & \\
\hline Sept. 10 & Oct. 16 & 16.28 & 15.35 & 1.19 & 1.34 & .57 & .78 & .19 & .23 & .81 & .83 & .37 & \\
\hline Sept. 13 & Oct. 23 & 17.28 & 15.01 & 1.12 & 1. 28 & .60 & .6 & .08 & .08 & .78 & .91 & .50 & \\
\hline Sept. 20 & Oct. 29 & 19.44 & 16.49 & .99 & 1.22 & .48 & .7 & .00 & .23 & .73 & .73 & .53 & \\
\hline Sept. 27 & Nov. 4 & 19.94 & 16.77 & .89 & 1.28 & .50 & .8 & .00 & .23 & .63 & .74 & .53 & \\
\hline Oct. 4 & Nov. 8 & 19.45 & 16.39 & .95 & 1.09 & .58 & .79 & .04 & .29 & .64 & .55 & .56 & 52 \\
\hline
\end{tabular}

The crop of 1911 was of excellent quality for wine making purposes, while that of 1912 was distinctly poor, yet the sugar content varies only about 3 grams at the final examinations given in Table 3 . This result agrees with our study of general crop samples in good and poor crop years, as shown in Bureau of Chemistry Bulletin 145.

The acid elements are more difficult and complex as to comparison. In total acid the crop of 1911 exceeds that of 1912 for the first several samples compared, but gradually declines until it falls below the latter. The final difference, however, is not marked. The fact that free tartaric acid in appreciable quantity continues present in the 1912 crop is important from a manufacturing point of view, because this acid can not be eliminated from the products except by the artificial introduction of a base such as potassium or calcium.

The fixed acids other than tartaric (malic) are interesting in that for the good crop year (1911) the values obtained in the early stages were much greater than in 1912, while at the end of the season the two crops were about alike. The total tartaric acid of the poor crop (1912) sensibly exceeded that of the $1911 \mathrm{crop}$ and the free tartaric acid markedly exceeded that found in 1911 in the early samples and at the time of harvesting still maintained this excess.

The remarks on the analytical results for cream of tartar given under "Crop of 1911" apply to the consideration of the results obtained for the juice samples analyzed in 1912. The juice samples of 1912 also show exceptions which, though not so marked, are noticeable. The varieties sampled in 1912 show, with one exception, an increase of cream of tartar as the fruit matured, whereas in 1911 the samples are not uniform in this regard. This lack of logical results in regard to the content of cream of tartar, and also other considerations, led us to examine whole fruit samples in 1912. The fruit sample was treated in such manner that the entire content of 
cream of tartar was recovered, so far as this could be accomplished in water solution. These data are presented in a subsequent section of this paper.

TABLE 4.-Increase of sugar and decrease of acid for certain periods, 1912.

[Results in grams per $100 \mathrm{cc}$.

SANDUSKY, OHIO.

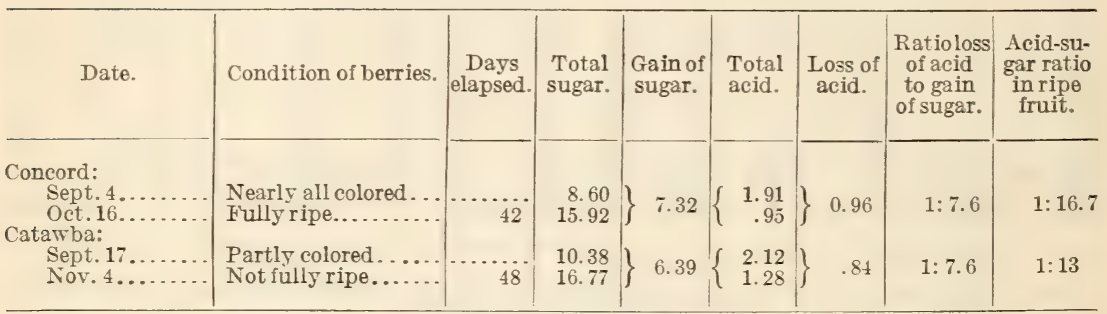

CHARLOTTESVILLE, VA.

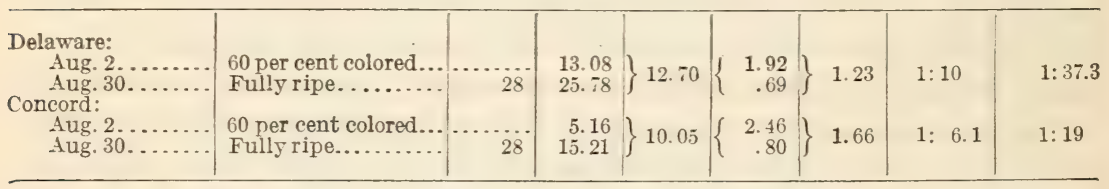

\section{COMPOSITION OF THE WHOLE FRUIT.}

A portion of each fruit sample used for the juice analysis in 1912 was taken to make a fairly complete analysis of the whole fruit used for the acid-sugar investigation. The method followed in taking and handling the samples for this work has been given with sufficient detail under "Sources and preparation of samples."

The apparent irregularity in the increased content of cream of tartar as the fruit matured and the fact that crystals of this salt are deposited in the fruit during ripening first suggested the complete exhaustion of the organic salts from the berries. Then the further considerations as to whether the total weight of acid present in the fruit really decreased during ripening or was simply reduced in percentage by reason of the influx of sap and by the formation of sugar in the fruit was a point requiring investigation. This latter question was suggested by some critical discussion of the results obtained in 1911, during which it was pointed out by colleagues in the Bureau of Chemistry that it had not been definitely shown that acid was eliminated during ripening, though this appeared from the results to be the case. This discussion led the authors to include in the work for 1912 determination of the volume in cubic centimeters, the specific gravity, and the exact weight in grams, of 100 berries from the composite sample taken for the juice analysis. There was also concluded a fairly complete ash analysis of a portion 
of this whole fruit sample. The physical examinations noted were made in triplicate and the average results used in the table. From these results, in connection with the analyses of the completely extracted fruit samples, some comparisons of definite value in regard to the actual weight content of acid in 100 berries at different periods of maturity may be drawn.

RELATIVE ACTUAL WEIGHT OF TOTAL ACID IN GREEN AND RIPE FRUTT.

The volume of the 100 berries was determined by displacement of water, and the specific gravity was determined by weighing first in air and then in water and calculating the gravity.

It was found necessary to rinse the berries with a weak solution of alcohol (10 to 15 per cent) in order to obviate the formation of air bubbles on the surface, which otherwise markedly interfered with both the volume measurement and the weighing for specific gravity.

The volume and weight of the Concord berries did not show marked changes in size of the fruit throughout the period of the examinations of the samples, but for Catawba there was a decided increase of about 39 per cent in volume and about 44 per cent in weight. It appears that this late-maturing variety for that season shows considerable change in size and weight of berries during the period from coloring to maturity.

On calculating the actual weight of acid in grams present for each sample of 100 berries examined there is shown in a positive manner, in Table 5, a fairly constant diminution in total weight of this ingredient. The percentage of acid in the water-exhausted sample is used for this calculation. There are some apparently abnormal results; that is, during some periods the actual weight of acid increased slightly, yet this is invariably reversed for the subsequent analysis and the comparison of the first samples and the last taken show a positive loss in total weight of acid present in 100 berries for all the crops analyzed. The data appear to establish the fact that there is a very decided loss in total weight of acid as the fruit ripens. The weight loss is in case of Concord, both at Charlottesville and Sandusky, approximately one-half the total acid found in the first sample. For Catawba the proportion falls slightly under one-half the original acid.

These results are such as should be expected from the analysis of juice samples, wherein it is shown in Table 1 that the fixed acids other than tartaric disappear to a marked extent as the fruit ripens. The results presented in Table 7 also support this contention. While it is also true that the total tartaric acid is shown by Table 1 to decline, this is not so marked and does not nearly account for the actual loss in weight of acid shown in Table 5. 
TABLE 5.-Measurements and weights of samples of 100 berries compared with percentage total acid and actual acid by weight in samples of 100 berries, 1912.

SANDUSKY, OHIO.

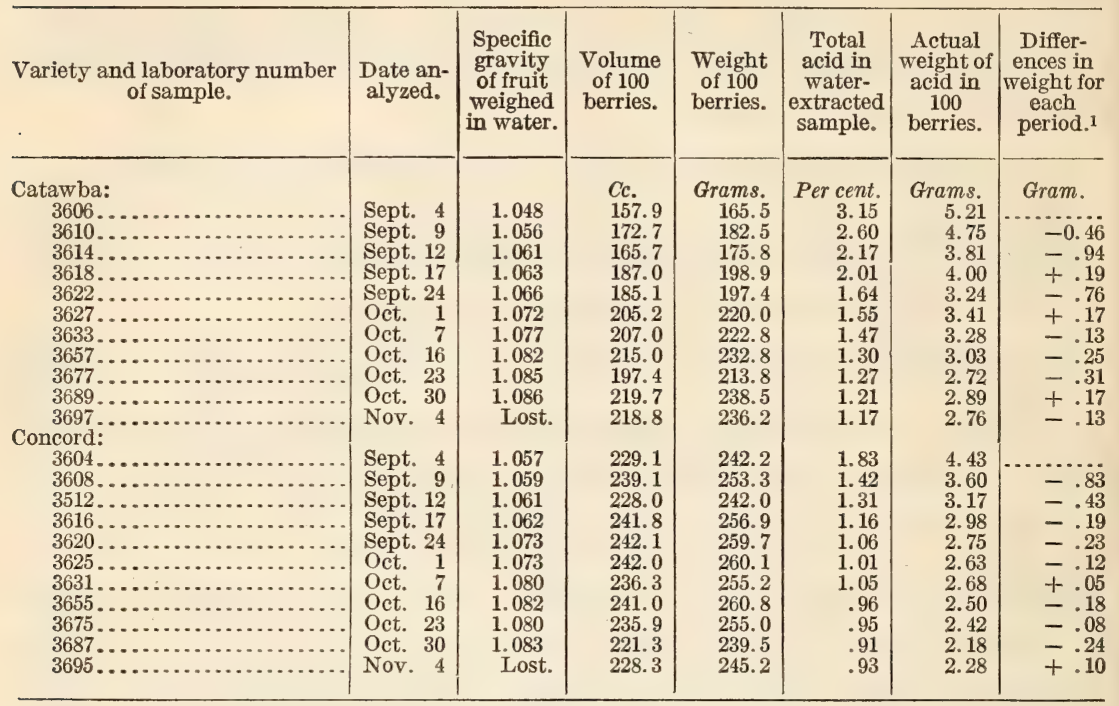

CHARLOTTESVILLE, VA.

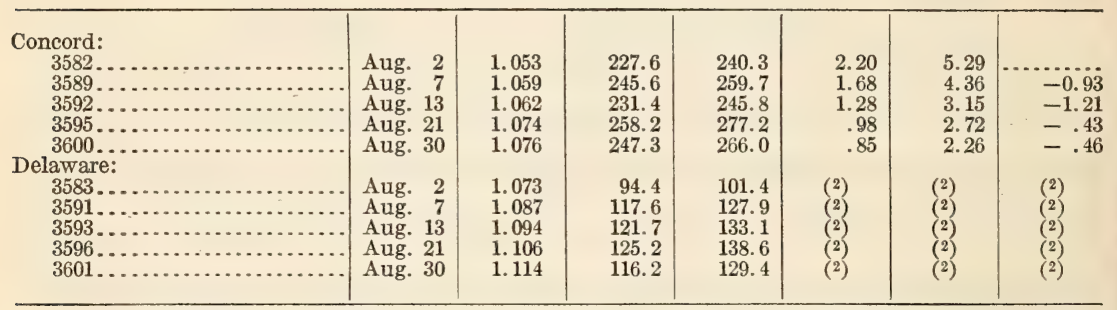

1 Total loss in weight of acid in 100 berries: Catawba, 2.45 grams; Concord (Sandusky), 2.15 grams; Concord (Charlottesville), 3.03 grams.

2 Data not complete.

\section{ANALYTICAL RESULTS ON THE WHOLE FRUIT SAMPLES.}

The data on the examinations made of whole-fruit samples are given in Table 6. These figures are necessarily percentages of the weighed fruit sample. Therefore, for the purpose of comparison, the results for sugar and acid of the juice samples given in Table 1 are calculated to percentages and these data for both juice and whole fruit samples are brought together in Table 7. 


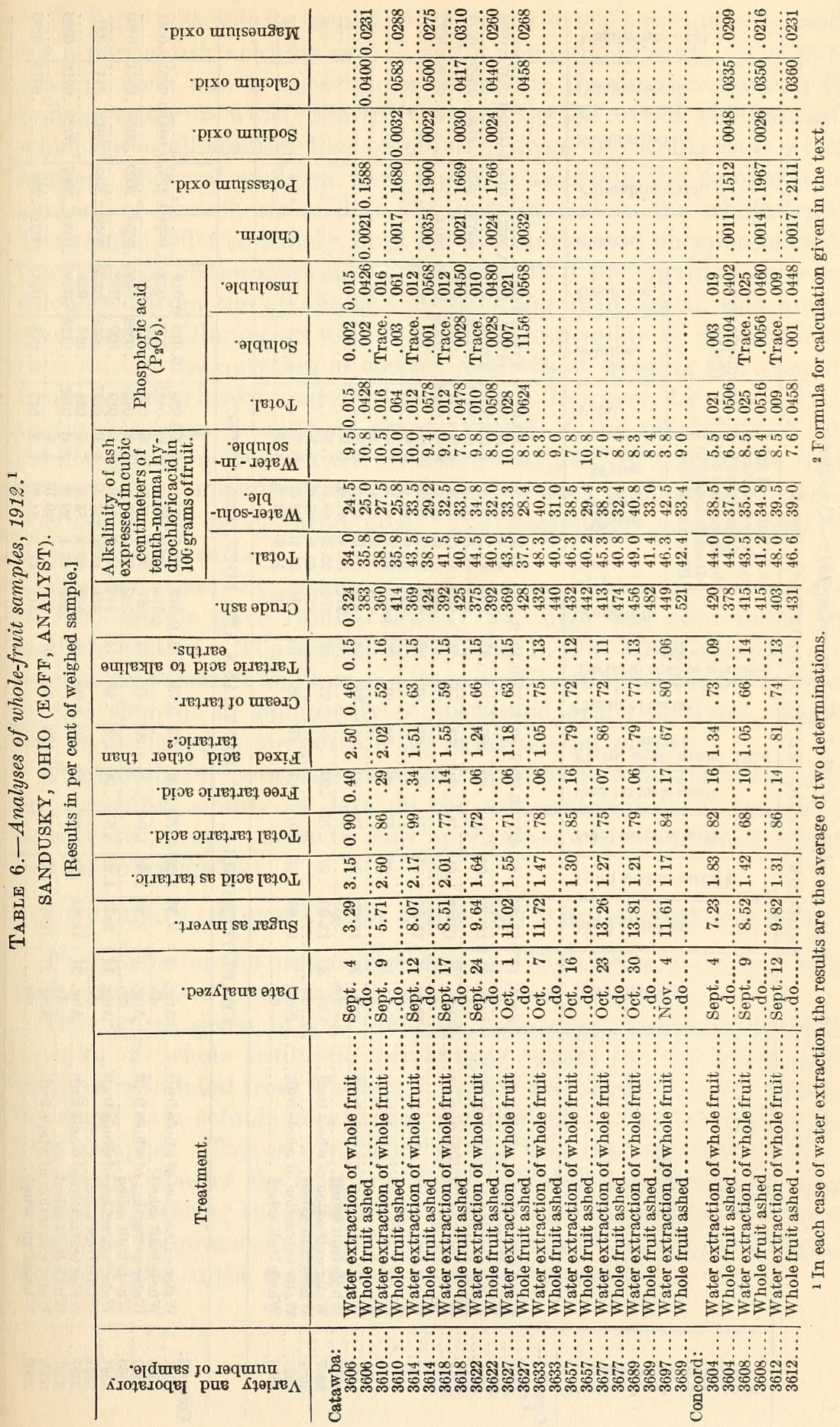




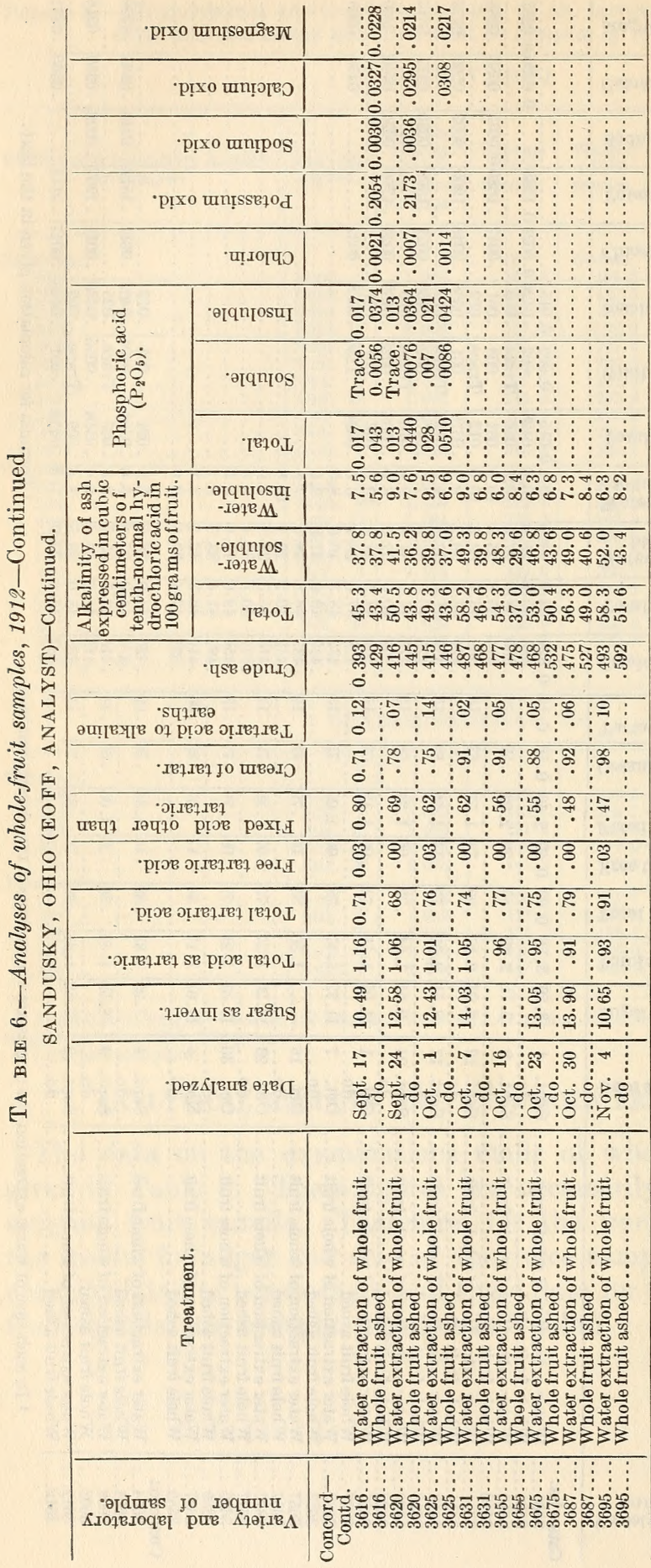

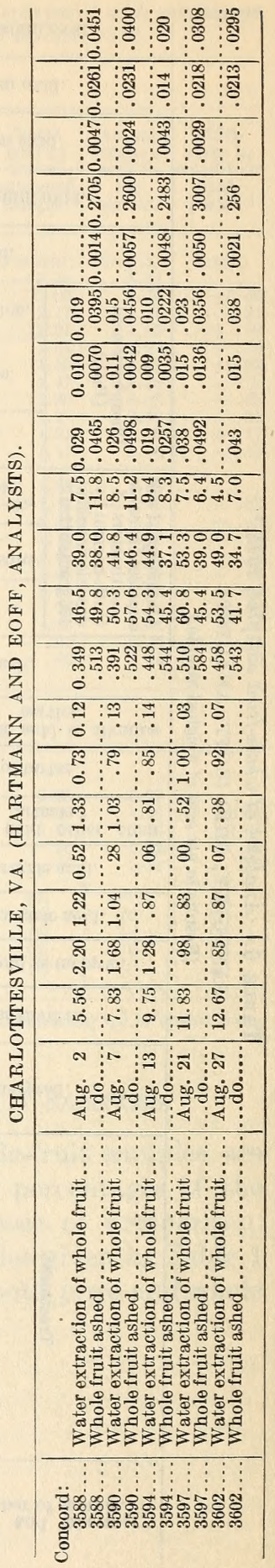


In Table 6 it will be seen that the water-extract sample was used for a partial ash analysis as well as for the organic work. The purpose in view was to ascertain whether the thorough extraction in boiling water to which the fruit was subjected would yield an ash which gave alkalinities like or different from the whole fruit when burned. Several analyses were made to ascertain the comparative content of phosphoric acid in the extract and in the whole fruit. The results differ so widely, both for alkalinities and phosphoric acid, that they do not support each other; that is, if the organic salts were calculated from the alkalinities of the whole fruit ashed, this would give results differing so widely as to be impossible of explanation, thus raising the question of correct methods of treating the sample. From careful checks made of our methods, however, by use of synthetic solutions the authors are convinced of the reliability of the results given by the water-extraction sample. It is possible that in ashing the whole fruit it was heated in such manner as to lose a portion of the alkali carbonates. The discrepancy is more marked as the fruit matures.

The fact that the attempt to determine chlorin in the waterextract sample gave results entirely too high has been noted in another section. The results for chlorin in the ashed samples are reasonably constant and have an important bearing on the occurrence of this element in supposedly sophisticated grape products, which will be discussed in a report on the experimental wines.

The results for potassium, sodium, calcium, and magnesium oxids are presented simply as data on the ash composition of pure and adulterated grape products, the application of which must await further investigation.

\section{COMPARISON OF RESULTS ON JUICE AND WHOLE-FRUIT SAMPLES.}

The results for the organic elements and the acid salts in the whole fruit samples are more readily compared from Table 7 .

The figures given in this table are percentage results for weighed samples of whole fruit and percentage results for the 1912 juice samples calculated from Table 1. It will be noted that the results for sugar as a soluble constituent are noticeably less on the whole fruit samples. This is explained by the fact that the seeds, skins, and woody fiber of the fruit is a part of the whole-fruit sample, and results in lowering the percentage content of sugar because the juice extracted by pressure always carries a greater percentage of sugar than is found in the residue left as marc or pomace. 
TABLE 7.-Comparison of sugar and acid content of juice samples and whole-fruit samples for 1912, compiled from Tables 1 and 6. (Hartmann, Eoff, and Ingle, analysts.)

[Results in per cent.]

SAMPLES FROM SANDUSKY, OHIO.

\begin{tabular}{|c|c|c|c|c|c|c|c|c|c|c|c|c|c|c|c|}
\hline \multirow{2}{*}{$\begin{array}{l}\text { Variety and } \\
\text { laboratory } \\
\text { number of } \\
\text { sample. } 1\end{array}$} & \multirow{2}{*}{ 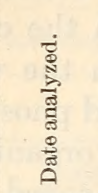 } & \multicolumn{2}{|c|}{$\begin{array}{l}\text { Sugar as } \\
\text { invert. }\end{array}$} & \multicolumn{2}{|c|}{$\begin{array}{l}\text { Totalacid } \\
\text { as tar- } \\
\text { taric. }\end{array}$} & \multicolumn{2}{|c|}{$\begin{array}{l}\text { Total tar- } \\
\text { taric acid. }\end{array}$} & \multicolumn{2}{|c|}{$\begin{array}{l}\text { Free tar- } \\
\text { taric acid. }\end{array}$} & \multicolumn{2}{|c|}{$\begin{array}{c}\text { Fixed } \\
\text { acid other } \\
\text { than tar- } \\
\text { taric. }\end{array}$} & \multicolumn{2}{|c|}{$\begin{array}{c}\text { Cream of } \\
\text { tartar. }\end{array}$} & \multicolumn{2}{|c|}{$\begin{array}{l}\text { Tartaric } \\
\text { acid to } \\
\text { alkaline } \\
\text { earths. }\end{array}$} \\
\hline & & 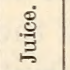 & 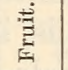 & $\stackrel{8}{\stackrel{8}{3}}$ & $\stackrel{\vec{\Xi}}{\vec{J}}$ & $\stackrel{8}{3}$ & 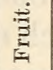 & $\frac{\dot{8}}{3}$ & 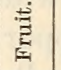 & 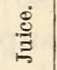 & 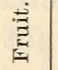 & 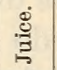 & $\underset{\Xi}{\stackrel{\Xi}{\Xi}}$ & 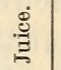 & $\mathfrak{E}_{\mathfrak{E}}^{\mathfrak{\Xi}}$ \\
\hline $\begin{array}{r}\text { oncor } \\
360\end{array}$ & & & & & & & & & & & & & & & \\
\hline 360 & pt. 4 & 8.19 & 7.23 & 1.82 & 1.83 & 0.89 & 0.82 & 0.45 & 0.16 & 1.15 & 1.34 & 0.48 & 0.73 & 0.06 & 0.09 \\
\hline $\begin{array}{l}36 \\
36 \\
36\end{array}$ & Sept. 9 & 9.48 & 8.52 & 1.42 & 1. 42 & .79 & .68 & .42 & .10 & .81 & 1.05 & .42 & .66 & .04 & .14 \\
\hline & Sept. 12 & 10.72 & 9.82 & 1.24 & 1.31 & .68 & .86 & .30 & .14 & .75 & .81 & .39 & .74 & .07 & .13 \\
\hline $\begin{array}{l}361 \\
361\end{array}$ & Sept. 17 & 11.44 & 10.49 & 1.08 & 1.16 & .68 & .71 & .25 & .03 & .61 & .80 & .47 & .71 & .05 & .12 \\
\hline & Sept. 24 & 13.28 & 12.58 & 1.00 & 1.06 & .72 & .68 & .21 & .00 & .53 & .69 & .56 & .78 & .07 & .07 \\
\hline & Oet. 1 & 13.85 & 12.43 & .95 & 1.01 & .72 & .76 & .17 & .03 & .51 & .62 & .58 & .75 & .09 & .14 \\
\hline & Oet. 7 & 14.78 & 14.03 & .92 & 1.05 & .69 & .74 & .12 & .00 & .51 & .62 & .63 & .91 & .07 & .02 \\
\hline & Oet. 16 & 14.82 & & .88 & .96 & .64 & .77 & .04 & .00 & .54 & .56 & .72 & .91 & .05 & .05 \\
\hline $\begin{array}{l}3 \\
3 \\
\end{array}$ & Oct. 23 & 14.77 & 13.05 & .87 & .95 & .62 & .75 & .00 & .00 & .52 & .55 & .76 & .88 & .01 & .05 \\
\hline $\begin{array}{l}3686 \\
3687\end{array}$ & Oet. 30 & 14.91 & 13.90 & .87 & .91 & .69 & .79 & .08 & .00 & .47 & .48 & .69 & .92 & .07 & .06 \\
\hline $\begin{array}{l}3694 \\
3695\end{array}$ & Nov. 4 & 14.50 & 10.65 & .88 & .93 & .82 & .91 & .16 & .03 & .39 & .47 & .77 & .98 & .05 & .10 \\
\hline $\begin{array}{l}\text { atawba: } \\
3605 . \\
3606 .\end{array}$ & Sept. 4 & 3.48 & 3.29 & 3.56 & 3.15 & 1.16 & .90 & .76 & .40 & 2.60 & 2.50 & .38 & .46 & .10 & .15 \\
\hline & Sept. 9 & 6.41 & 5.71 & 2.90 & 2.60 & 1.04 & .86 & .62 & .29 & 2.07 & 2.02 & .39 & .52 & .10 & .16 \\
\hline & Sept. 12 & 8.89 & 8.07 & 2.36 & 2.17 & .86 & .99 & .43 & .34 & 1. 71 & 1.51 & .44 & .63 & .08 & .15 \\
\hline & Sept. 17 & 9.85 & 8.51 & 2.01 & 2.01 & .85 & .77 & .45 & .14 & 1.37 & 1.55 & .43 & .59 & .07 & .15 \\
\hline & Sept. 24 & 10.72 & 9.64 & 1.65 & 1.64 & .69 & .72 & .19 & .06 & 1.21 & 1.24 & .50 & .66 & .10 & .15 \\
\hline & Oct. 1 & 12.01 & 11.02 & 1. 54 & 1.55 & .75 & .71 & .29 & .06 & 1.01 & 1.18 & .51 & .63 & .06 & .15 \\
\hline 3 & Oet. 7 & 12.93 & 11.72 & 1. 43 & 1.47 & .75 & .78 & .22 & .06 & .96 & 1.05 & .57 & .75 & .08 & .13 \\
\hline & Joct. 16 & 14.31 & & 1.25 & 1.30 & .73 & .85 & .21 & .16 & .77 & .79 & .57 & .72 & .06 & .12 \\
\hline $\begin{array}{l}3 \\
3\end{array}$ & Oet. 23 & 14.01 & 13.26 & 1. 19 & 1.27 & .60 & .75 & .07 & .07 & .85 & .86 & .55 & .72 & .09 & .11 \\
\hline $\begin{array}{l}3 \\
3 \\
\end{array}$ & Oet. 30 & 15.31 & 13.81 & 1.13 & 1.21 & .70 & .79 & .21 & .05 & .68 & .79 & .53 & .77 & .05 & .13 \\
\hline $\begin{array}{l}3 \\
3 \\
3\end{array}$ & Nov. 4 & 15.54 & 11.61 & 1. 19 & 1.17 & .78 & .84 & .21 & .17 & .69 & .67 & .66 & .80 & .05 & .06 \\
\hline
\end{tabular}

SAMPLES FROM CHARLOTTESVILLE, VA.

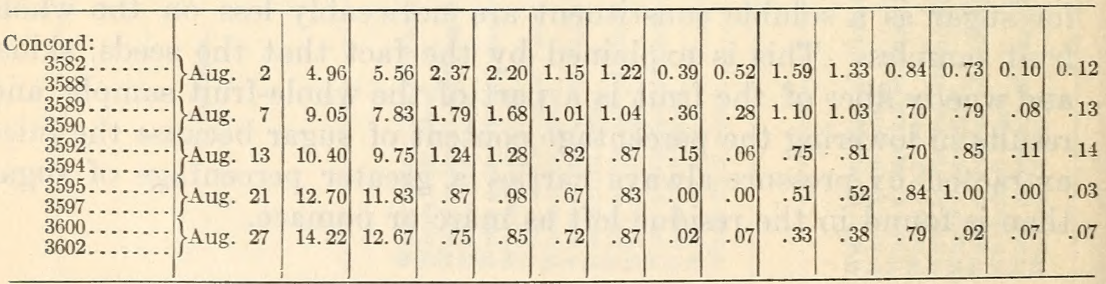

1 While the juice and whole-fruit samples for each date are portions of one original field sample, they are necessarily given different numbers in the record. In this table both numbers are entered; the first in each case is the juice sample and the second is the whole-fruit sample. 